\title{
Penentuan Kandungan Logam di Dalam Sedimen Waduk Gajah Mungkur dengan Metode Analisis Aktivasi Neutron Cepat
}

\author{
Sudaryo ${ }^{1}$, Sutjipto ${ }^{2}$ \\ ${ }^{1}$ Sekolah Tinggi Teknologi Nuklir - Batan Yogyakarta \\ ${ }^{2}$ Pusal Teknologi Aksclerator dan Proses Bahan - Batan Yogyakarta
}

\begin{abstract}
ABSTRAK
KANDUNGAN LOGAM DI DALAM SEDIMEN WADUK GAJAH MUNGKUR KABUPATEN WONOGIRI. Penclitian mengenai kandungan logam pada sedimen waduk Gajah Mungkur kabupaten Wonogiri telah dilakukan. Penelitian ini bertujuan untuk menentukan kandungan unsur logam di dalam waduk Gajah Mungkur kabupaten Wonogiri dengan metode AANC. Pencuplikan sedimen dilakukan di 3 (tiga) lokasi di daerah waduk tersebut. Pencuplikan pada bulan April 2008 dengan waktu pencuplikan pada jam 10.00-14.00 WIB. Kandungan unsur logam di waduk ditentukan dengan menggunakan Generator Neutron SAMFS J-25 serta peralatan spektrometer gamma dengan detektor $\mathrm{NaI}(\mathrm{Tl})$ serta standar pembanding SRM 2704 (buffalo river sediment, BRS) dari NIST. Hasil penelitian menunjukkan bahwa konsentrasi kandungan unsur logam yang tersebar didalam waduk pada lokasi 1 hingga 3 untuk Fe: 7,4 $32 \%$ Al: $12-16 \%$; Si: $40 \%$ dan Cr total: $3-16$ ppm. Adapun akurasi untuk unsur logam $\mathrm{Fe}, \mathrm{Al}, \mathrm{Si}$ dan $\mathrm{Cr}$ total mempunyai kisaran: 5,25 - 10,75\%; presisi: 10,99 - 14,25\% dan batas deteksi untuk $\Lambda \mathrm{l}=1$ $\%, \mathrm{Na}=0,14 \%, \mathrm{Mg}=0,05 \%, \mathrm{Si}=2 \%, \mathrm{Fe}=1 \%$ dan $\mathrm{Cr}=0,01 \mathrm{ppm}$. Didasarkan data penelitian menunjukkan bahwa di dalam sedimen waduk telah mengalami pencemaran unsur logam berat, utamanya unsur Cr total.
\end{abstract}

Kata kunci:Sedimen, analisis aktivasi neutron cepat (AANC), generator neutron, logam-logam, SRM 2704

\section{ABSTRACT}

METAL CONTENTS IN THE GAJAH MUNGKUR ACCUMULATING BASIN SEDIMENT OF WONOGIRI REGENCY. Rescarch about metals content in the Gajah Mungkur accumulating basin sediment of Wonogiri regency has been done. This study aims to determine the metals content in a sediment of the accumulating basin by using AANC method. Sediment sampling conducted in 3 (three) locations in the accumulating basin area on April 2008 with a sampling time at 10:00 am to 14:00 pm. Content of metal elements was determined by using neutron generator SAMES J-25 and gamma spectrometry equipment with the detector $\mathrm{NaI}(\mathrm{Tl})$ as well as the comparison standard of SRM 2704 (Buffalo river sediment, BRS) from NIST. The results showed that the concentration of metal content seattered at locations 1 to 3 for Fe: $7,4-32 \% ; \mathrm{Al}: 12-16 \% ; \mathrm{Si}: 40 \%$ and the total of $\mathrm{Cr}: 3$ to $16 \mathrm{ppm}$. The accuracy for metallic elements $\mathrm{Fe}, \mathrm{Al}, \mathrm{Si}$ and $\mathrm{Cr}$ have a total range: 5.25 to $10.75 \%$; precision: 10.99 to $14.25 \%$ and the detection limit for $\mathrm{Al}-1 \%, \mathrm{Na}-0.14 \%, \mathrm{Mg}-0.05 \%, \mathrm{Si}-2 \%, \mathrm{Fe}=1 \%$ and $\mathrm{Cr}=0.01 \mathrm{ppm}$. Based on data, it showed that in the accumulating basin sediment have experienced contamination of heavy metal element, mainly $\mathrm{Cr}$ element totalizes.

Keywords: Sediment, FAANC, neutron generators, metals, SRM 270

\section{PENDAHULUAN}

Waduk Gajah Mungkur adalah sebuah waduk yang terletak $3 \mathrm{~km}$ di selatan Kota kabupaten Wonogiri, Provinsi
Jawa Tengah. Perairan danau buatan ini dibuat dengan membendung sungai terpanjang di pulau Jawa yaitu sungai Bengawan Solo. Mulai dibangun di akhir tahun

* Corresponding author. Tel/Fax: (0274) 48085

Email address: - 


\section{Jurnal Forum Nuklir, tahun, Volume (Nomor)}

1970-an dan mulai beroperasi pada tahun 1978. Waduk dengan wilayah seluas kurang lebih 8800 ha di 7 kecamatan ini bisa mengairi sawah seluas 23600 ha di daerah Sukoharjo, Klaten, Karanganyar dan Sragen. Selain untuk memasok air minum Kota Wonogiri juga menghasilkan listrik dari PLTA sebesar 12,4 MegaWatt. Sedimen adalah hasil proses erosi, baik berupa erosi permukaan, erosi parit, atau erosi tanah lainnya ${ }^{[1]}$. Sedimen umumnya mengendap dibagian bawah kaki bukit, didaerah genangan air, sungai, dan waduk ${ }^{[2]}$. Sedimen merupakan media yang banyak mengandung unsur logam berat, yaitu logam yang sangat berbahaya bagi makhluk hidup. Logam-logam tersebut sangat sulit mengalami pelapukan baik secara fisika, kimia maupun biologi. Ada beberapa faktor yang mempengaruhi sedimen yang terangkut dalam air sungai antara lain: 1 . Ukuran sedimen yang masuk ke badan sungai. 2 . Karakteristik saluran yaitu morfologi sungai, tingkat kekasaran dasar sungai, kemiringan sungai dan debit air. 3. Karakteristik fisik partikel sedimen. Jenis sedimen sangat dipengaruhi oleh ukuran butir. Untuk jenis liat mempunyai ukuran butir: $<0.0039$, debu: $0.0039-$ 0.0625 , pasir: $0.0625-2,0$ dan pasir besar: $2,0-64,0$ $\mathrm{mm}$. Di samping itu, sedimen dapat mempengaruhi kualitas air. Sedimen tersebut dibedakan menjadi 2 (dua) kelompok besar, yaitu: 1. Sedimen melayang (suspended material) terdiri dari: a. Sedimen non-organik yang meliputi pasir, debu, tanah liat dan koloidalkoloidal yang ada dalam air sungai. b. Sedimen organik yang meliputi unsur-unsur tanaman dan hewan baik yang hidup atau mati yang terlarut dalam aliran sungai. 2 . Sedimen terlarut (dissolved material) yang terdiri dari: a. Larutan non-organik yang meliputi unsur-unsur mineral, logam. gas dan unsur radioaktif. b. Larutan organik yang meliputi unsur-unsur organik yang bersifat kompleks sebagai hasil proses-proses fotosintesis, metabolisme dan dekomposisi jaringan tanaman dan hewan yang hidup di pertanian.

Sedimen dengan ukuran kecil seperti lempung dapat diangkut aliran sungai dengan bentuk terlarut (wash load). Unluk ukuran yang lebih besar seperti pasir cenderung bergerak dengan cara meloncat. Partikel yang lebih besar dari pasir bergerak dengan cara merayap atau menggelinding di dasar sungai (bed load). Sedimen yang terdapat di sungai pada umumnya merupakan produk dari pelapukan batuan yang dipengaruhi oleh lingkungan, terutama iklim. Pelapukan batuan menghasilkan partikel-partikcl tanah, karena pengaruh tenaga kinetis air hujan dan aliran air permukaan, maka pertikelpertikel tanah tersebut akan terangkut ke tempat yang lcbih rendah dan masuk ke dalam sungai.

Endapan (sedimen) dan koloidal serta bahan terlarut juga dapat berasal dari adanya bahan buangan industri yang berbentuk padat ${ }^{[3]}$. Bahan buangan industri yang berbentuk padat jika tidak dapat larut sempurna akan mengendap didasar sungai, dan yang larut sebagian akan menjadi koloidal. Endapan sebelum sampai ke dasar sungai akan melayang di dalam air bersama-sama dengan koloidal. Endapan dan koloidal yang melayang didalam air akan menghalangi masuknya sinar matahari kedalam lapisan air, schingga akan mengganggu proses fotosintesis mikroorganisme.

Waduk merupakan perairan buatan yang merupakan tempat bermuaranya sungai-sungai disekitarnya, sehingga kondisi waduk sangat dipengaruhi oleh alam sekitar. Salah satu waduk besar di provinsi Jawa Tengah adalah waduk Gajah Mungkur di kabupaten Wonogiri, dan sampai saat ini merupakan salah satu waduk yang sangat bermanfaat bagi penduduk sekitar untuk pengairan, perikanan, pembangkit listrik, dan tempat wisata. Di sepanjang sungai-sungai yang bermuara pada waduk tersebut terdapat banyak sumber pencemar seperti yang berasal dari pabrik, pemukiman warga, maupun kegiatan lain yang semuanya mempunyai potensi untuk memberikan sumbangan polutan yang sangat membahayakan. Sumber bahaya tersebut dapat diketahui dengan cara menganalisis kandungan unsur yang tcrdapat di dalam air ataupun sedimen waduk.

Didasarkan uraian tersebut di atas, maka penelitian ini bertujuan untuk mengetahui kandungan logam pencemar di sedimen waduk Gajah Mungkur kabupaten Wonogiri menggunakan metode AANC sebagai salah satu upaya pemanfaatan akselerator.

\section{METODE}

\section{Alat Penelitian}

Alat-alat yang digunakan adalah Gencrator neutron Sames Type J25-150 keV/2 mA, scperangkat spektrometer- $\gamma$ : detektor HPGe tingkat konsentrasi kemurnian 106 atom $\mathrm{m}-3$, penganalisis salur ganda (MCA), model accuspec $\mathrm{A}$, komputer dengan operasi sistem DOS, timbangan, ayakan (100 mesh), vial polietilen dan stopwatch.

\section{Bahan Penelitian}

Bahan-bahan yang digunakan adalah Sumber standar Eu152, Cs-137, Co-60 dan SRM 2704 (buffalo river sediment, BRS) dari NIST serta cuplikan sedimen dari waduk Gajah Mungkur kabupaten Wonogiri, Cuplikan sedimen diambil pada April 2008 yang berasal dari 3 titik lokasi waduk Gajah Mungkur

\section{Metode sampling}

Waktu pengambilan cuplikan tersebut adalah pada saat musim kemarau yaitu pada bulan april 2008 di 3 titik lokasi waduk Gajah Mungkur kabupaten Wonogiri pada bulan April 2008 antara jam 10.00-15.00 WIB. Hal ini dimaksudkan agar cuplikan sedimen lebih mudah diambil karena debit airnya kecil sehingga waduk lebih dangkal. Sclain itu diharapkan juga unsur-unsur yang mengendap dalam sedimen lebih banyak. Lokasi 1 diambil pada aliran masuk waduk dengan kondisi berupa pasir. Lokasi 2 diambil didekat karamba dengan kondisi berupa pasir dan debu agar diketahui kontribusi karamba tersebut terhadap kondisi sedimen waduk. Lokasi 3 diambil pada aliran keluaran waduk di lokasi plasa (istilah 
bahasa jawa yang memiliki arti pelataran desa kondisi berupa liat) dengan harapan agar dapat diketahui apakah terdapat perubahan kondisi yang terjadi di waduk (lihat lampiran).

Tiap-tiap lokasi diambil sedimen kurang lebih 1,5 kg. Untuk memperluas permukaan ukuran partikel-partikel sedimen, cuplikan tersebut dihaluskan dengan cara ditumbuk secara manual untuk selanjutnya diayak dengan menggunakan ayakan ukuran 100 mesh. Untuk keperluan iradiasi, dilimbang 200-250 mg dan dimasukkan ke dalam vial.

\section{Iradiasi, Pencacahan Dan Perhitungan Kandungan Cuplikan}

Cuplikan sedimen maupun SRM-2704 (buffalo river sediment, BRS) dari NIST yang telah dimasukkan dalam vial diiradiasi dengan generator neutron SAMES J-25$150 \mathrm{keV} / 2 \mathrm{~mA}$. Selanjutnya dilakukan pencacahan dengan seperangkat spektrometer- $\gamma$ yang terdiri dari detektor HPGe tingkat konsentrasi kemurnian 106 atom m3, penganalisis salur ganda (MC $\Lambda$ ) model accuspec $\Lambda$, komputer dengan operasi sistem DOS spektrometer gamma. Perhitungan kandungan logam di dalam sedimen dilakukan dengan membandingkan laju cacah cuplikan dan standar.

\section{HASIL DAN PEMBAHASAN}

Pada dasarnya perairan waduk selalu mengalami perubahan, baik harian, bulanan, musiman, maupun jangka panjang yaitu terjadi perubahan dari fase oligotrofik (waduk baru) menuju fase eutrofik (waduk relatif lama). Perubahan terjadi karena adanya faktor dari dalam maupun dari luar. Faktor dari dalam (cutochthonous) dapat berupa sedimen di dasar perairan yang melepaskan unsur tertentu ke dalam air. Pelepasan unsur itu ditentukan antara lain oleh reaksi air yang berdekatan dengan sedimen dan kandungan oksigen terlarut. Sementara faktor dari luar (allochlonous) yakni berupa masukan senyawa air limbah yang dibawa oleh aliran sungai, termasuk padatan tersuspensi dari proses erosi tanah daerah aliran sungai selain juga adanya pemanfaatan waduk untuk budi daya ikan berupa keramba jaring apung (KJA). Dengan demikian, masukan zat hara secara kontinu ke perairan waduk akan senantiasa menimbulkan dan mempercepat pencemaran air.

Sedimen didapatkan dari pengambilan cuplikan memiliki jenis yang berbeda-beda, tergantung lokasi pengambilan cuplikan disctiap titik. Jenis sedimen yang didapatkan di waduk Gajah Mungkur adalah sebagai berikut : Untuk lokasi 1, berupa pasir, lokasi 2, berupa pasir dan debu serta lokasi 3 , berupa liat. Perbedaan jenis sedimen tersebut dipengaruhi oleh struktur sedimen waduk Gajah Mungkur, berbagai macam kegiatan manusia yang ada disekitar waduk, serta kegiatan manusia yang masuk ke sungai-sungai yang bermuara ke waduk.

Polutan air dapat dibedakan menjadi dua jenis yaitu buangan degradable dan nondegradable. Buangan degradable adalah buangan yang dapat terdekomposisi atau dapat dihilangkan dari perairan dengan proses biologis alamiah, sedangkan buangan nondegradable adalah buangan yang tidak dapat dihilangkan dari perairan dengan proses biologis alamiah ${ }^{[3]}$.

Masuknya polutan dalam air yang tidak dapat larut dalam air membawa partikel ke suatu tempat dan mengendap dilokasi tertentu. Sedimen tersebut mempengaruhi sedimen yang terjadi secara alamiah yang berasal dari produk pelapukan batuan dan erosi sungai. Sampai saat ini Indonesia belum memiliki peraturan yang mengatur tentang kadar maksimum pencemar yang boleh terkandung dalam sedimen sungai di Indonesia. Michacl Buchman menerbitkan Screening Quick Reference Tuble for Inorganics in Solid sebagai acuan untuk menentukan tingkat pencemaran di dalam sedimen oleh pertikel nonorganik.

Salah satu metoda yang digunakan untuk mengetahui konsentrasi unsur logam dalam sedimen adalah metoda analisis aktivasi neutron cepat (APNC). Pemilihan reaksi yang tepat akan meningkatkan analisis unsur yang dikehendaki dan menekan reaksi pengaktifan unsurunsur lain yang dapat mengganggu analisis. Rcaksi inti yang sering digunakan pada APNC adalah reaksi inti (n, p), $(n, \alpha)$ dan $(n, 2 n)^{[4]}$.

Aktivitas awal (Cps0) dari masing-masing standar maupun cuplikan sedimen saat keluar dari fasilitas iradiasi di akselerator ditentukan dengan rumus:

$$
\mathrm{Cps}_{0}=\mathrm{Cps}_{\mathrm{t}} \mathrm{e}^{0,693 \mathrm{t} / \mathrm{T}}
$$

Cpso $=$ aktivitas awal $(\mathrm{cps}) ;$

Cpst $=$ Aktivitas pada saat dicacah $(\mathrm{cps})$

$\mathrm{t}_{\mathrm{d}}=$ waktu tunda (hari);

$\mathrm{T}$ - Waktu paro dari nuklida logam (hari)

Perambatan ralat untuk Persamaan (1) adalah:

$\Delta \mathrm{Cps}_{0}=\sqrt{\left(\mathrm{e}^{0,693 . \mathrm{t}, \mathrm{T}}\right)^{2}\left(\Delta \mathrm{Cps}_{\mathrm{t}}\right)^{2}+\left(\frac{0,693 \cdot \mathrm{Cps} \mathrm{t}_{\mathrm{t}}}{\mathrm{T}}\right)^{2}(\Delta \mathrm{t})^{2}}$

Setelah dihitung harga $\mathrm{Cps} 0$ dari masing-masing konsentrasi cuplikan maupun standar, maka konsentrasi unsur logam di dalam cuplikan sedimen dapat diketahui. Adapun perumusan yang digunakan untuk menghitung konsentrasi adalah: 


\section{Jurnal Forum Nuklir, tahun, Volume (Nomor)}

$$
\mathrm{W}_{\text {Cupl }}=\frac{\mathrm{Cps}_{0 \mathrm{Cupl}}}{\mathrm{Cps}_{0 \mathrm{Std}}} \times \mathrm{W}_{\mathrm{Std}}
$$

Wcuplikan = kandungan cuplikan;

WStd = kandungan standar;

Cps0 = laju cacah saat aktivasi dihentikan

Cpst = laju cacah yang diketahui dari pencacahan

Tabel 1. Jenis Unsur Logam Yang Terdeteksi Dari Setiap Lokasi

\begin{tabular}{cccc}
\hline \multirow{2}{*}{$\begin{array}{c}\text { Unsur } \\
\text { Logam }\end{array}$} & \multicolumn{3}{c}{ Lokasi } \\
\cline { 2 - 4 } $\mathrm{Fe}$ & $\gamma^{\prime}$ & 2 & 3 \\
$\mathrm{Al}$ & $x$ & $\gamma^{\prime}$ & $\gamma^{\prime}$ \\
$\mathrm{Cr}$ & $\gamma^{\prime}$ & $\gamma^{\prime}$ & $x$ \\
Si & $\gamma^{\prime}$ & $x$ & $x$ \\
\hline
\end{tabular}

Kelerangan: $\sqrt{ }$ menyatakan unsur yang terdetcksi dan $x$ menyatakan unsur tidak terdeteksi.

Berikut ini dinyatakan rumus untuk menghitung presisi, akurasi dan batas deteksi. Presisi menunjukkan kesesuaian antara beberapa pengulangan yang diukur dengan cara yang sama. Presisi dinyatakan dalam bentuk nilai relative standard deviation (RSD) dengan persamaan.

$$
\mathrm{RSD}=\frac{\mathrm{s}}{\mathrm{x}} \times 100 \%
$$

$$
\mathrm{s}=\sqrt{\sum_{i=1}^{n} \frac{|\mathrm{x}-\overline{\mathrm{x}}|^{2}}{(\mathrm{n}-1)}}
$$

$\mathrm{s}=$ simpangan ;

$\mathrm{x}-$ hasil uji

$\overline{\mathrm{x}}=$ hasil uji rerata ;

$\mathrm{n}=$ jumlah pengulangan

Akurasi merupakan kedekatan scbuah hasil uji atau rerata hasil uj: ke nilai sebenarnya (true valuc). Akurasi dinyatakan dalam bentuk persamaan:

$$
\text { Akurasi }=\left|\frac{W_{\text {Tenukur }}-W_{\text {Sesungguhga }}}{W_{\text {Sesunggulyya }}}\right| \times 100 \%
$$

Batas deteksi (mL) untuk unsur logam di dalam sedimen dapat ditentukan dengan persamaan sebagai berikut ${ }^{[5]}$ :

$$
\mathrm{m}_{\mathrm{L}}=\mathrm{m}_{\mathrm{S}}(\mu \mathrm{g}) \frac{(2,71+4,65 \sqrt{\mathrm{B}})}{\mathrm{W}(\mathrm{mg}) \cdot 10^{3} \cdot \mathrm{a}_{\mathrm{S}}}(\mathrm{ppm})
$$

$\mathrm{mL}=$ batas deteksi

$\mathrm{mS}=\quad$ berat unsur dalam cuplikan standar

W- berat cuplikan

$\mathrm{B}=$ jumlah cacah latar

$\mathrm{aS}=\quad$ jumlah cacah standar

Akurasi, presisi dan batas deteksi pada penelitian ini ditentukan didasarkan pada Persamaan (1) sampai (7) dengan menggunakan SRM 2704 (buffalo river sediment, BRS). Untuk unsur logam $\mathrm{Fe}, \mathrm{Al}$, Si dan $\mathrm{Cr}$ akurasinya mempunyai kisaran: 5,25 - 10,75\%; presisi: $10,99-14,25 \%$ dan batas deteksi untuk $\mathrm{Fe}-1 \%, \mathrm{Al}=$ $1 \%, \mathrm{Si}-2 \%$ dan $\mathrm{Cr}=0,01 \mathrm{ppm}$

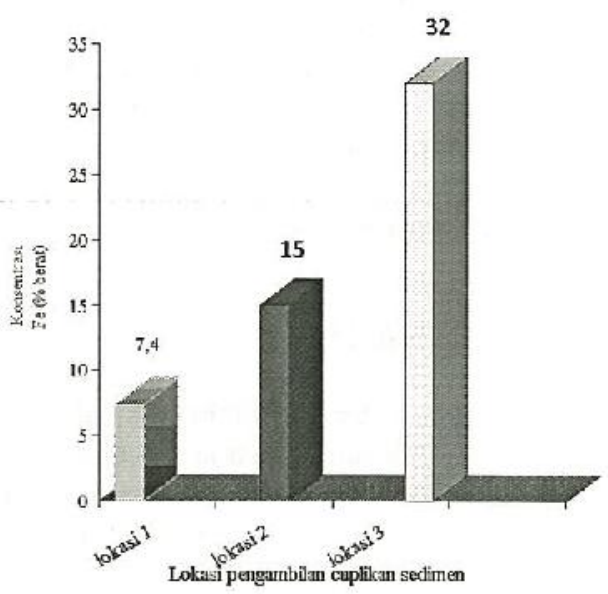

Gambar 1. Konsentrasi Fe ( $\%$ Berat) di dalam Sedimen Setiap Lokasi di Waduk Gajah Mungkur

$\Lambda$ nalisis kuantitatif terhadap kandungan unsur di dalam cuplikan sedimen didasarkan pada Persamaan (1) sampai (4). Adapun hasil konsentrasi unsur logam Fe di masingmasing lokasi 1, 2 dan 3 adalah ditunjukkan pada Gambar 1. Gambar 1 menunjukkan bahwa konsentasi unsur logam Fe pada sedimen di lokasi 1 (aliran air masuk waduk), 2 (dekat keramba ikan) dan 3 (aliran air ke luar) di waduk Gajah Mungkur.

Distribusi konsentrasi unsur logam Fe terhadap total keseluruhan unsur logam Fe di dalam waduk Gajah Mungkur ditunjukkan pada Gambar 2. Gambar 2 menunjukkan perbandingan distribusi unsur logam tersebut di dalam masing-masing sedimen pada lokasi 1,2 dan 3 adalah 14, 27 dan $59 \%$ terhadap total keseluruhan unsur logam Fe di dalam waduk. 


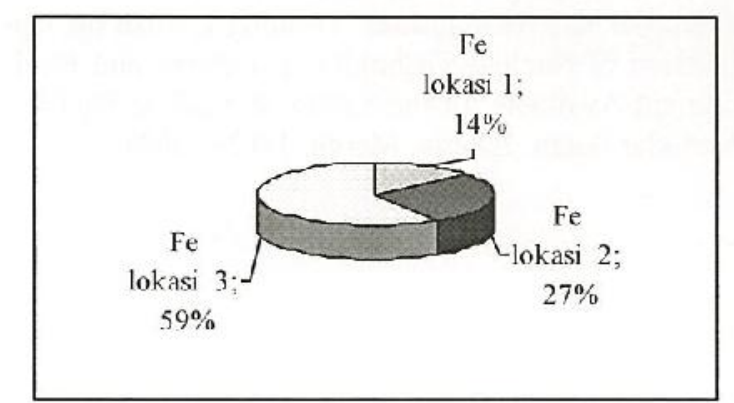

Gambar 2. Distribusi Konsentrasi Unsur Logam Fe Terhadap Total Keseluruhan Unsur Logam Fe di Dalam Waduk Gajah Mungkur

Berdasar data tersebut menunjukkan bahwa pergerakan aliran air pada lokasi 1 lebih besar dibandingkan pada lokasi 2 maupun 3. Lokasi 3 merupakan sistem pengendali untuk keluarnya air atau pengendali ketinggihan waduk sehingga kecepatan aliran airnya relatif lebih lambat dibandingkan dengan lokasi yang lain. Sedimen yang terdapat di sungai pada umumnya merupakan produk dari pelapukan batuan yang dipengaruhi oleh lingkungan, terutama iklim. Pelapukan batuan menghasilkan partikel-partikel tanah yang mengandung unsur logam, karena pengaruh tenaga kinetis air hujan dan aliran air permukaan, maka pertikel-pertikel tanah tersebut akan terangkut ke tempat yang lebih rendah dan masuk ke dalam sungai. Sedimen umumnya mengendap di daerah genangan banjir, di saluran air, sungai, dan waduk. Disebabkan hal tersebut, maka akumulasi/ pengendapan unsur logam $\mathrm{Fe}$ di dalam sedimen pada lokasi 3 lebil besar dibandingkan pada lokasi 2 maupun 1 .

Ada beberapa faktor yang mempengaruhi sedimen yang terangkut dalam air sungai antara lain: 1. Ukuran sedimen yang masuk ke badan sungai. 2. Karakteristik saluran yaitu morfologi sungai, tingkat kekasaran dasar sungai, kemiringan sungai dan debit air. 3. Karakteristik fisik partikel sedimen. Endapan (sedimen) dan koloidal serta bahan terlarut juga dapat berasal dari adanya bahan buangan industri yang berbentuk padat (2). Bahan buangan industri yang berbentuk padat jika tidak dapat larut sempurna akan mengendap didasar sungai, dan yang larut sebagian akan menjadi koloidal.

Gambar 3 menunjukkan bahwa konsentrasi $\mathrm{Al}$ pada lokasi 1,2 dan 3 di waduk Gajah Mungkur.

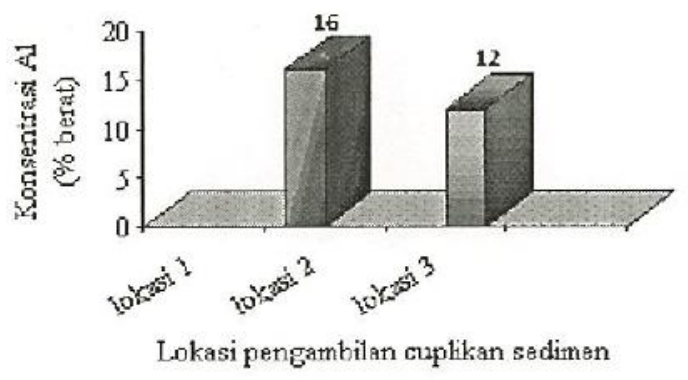

Gambar 3. Konsentrasi Al (\% Berat) di dalam Sedimen Setiap Lokasi di Waduk Gajah Mungkur

Gambar 4 menunjukkan bahwa distribusi unsur logam Al terhadap total keseluruhan unsur logam Al di dalam waduk Gajah Mungkur. Pada lokasi 1 konsentrasi Al tidak tcrdetcksi. Adanya unsur logam Al pada lokasi 2 dimungkinkan berasal dari adanya kegiatan perikanan yang menycbabkan terendapkannya unsur tersebut pada sedimen. Konsentrasi Al pada lokasi 2 sebesar $16 \%$, sedangkan pada lokasi 3 sebesar $12 \%$, atau distribusi konsentrasi unsur logam tersebut di dalam sedimen sebesar 57 dan $43 \%$. Hal tersebut dikarenakan pergerakan maupun lepasnya unsur logam Al dari sedimen.

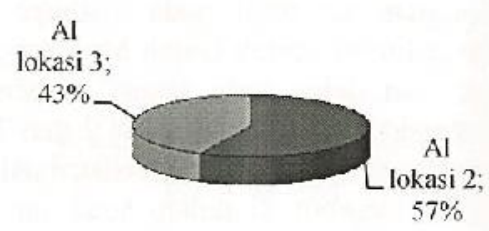

\section{Gambar 4. Distribusi Konsentrasi Unsur Logam A Terhadap Total Keseluruhan Unsur Logam Al di dalam Waduk Gajah Mungkur}

Untuk logam Si sebagian besar hanya terendapkan pada sedimen pada lokasi 1 , sedangkan lokasi 2 dan 3 tidak terdeteksi. Adapun konsentrasi Si sebesar $40 \%$.

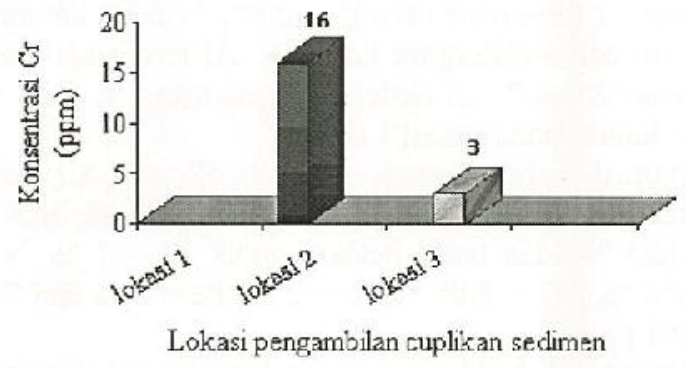

Gambar 5. Konsentrasi Cr (ppm) di dalam Sedimen Setiap Lokasi di Waduk Gajah Mungkur

Gambar 5 menunjukkan bahwa konsentrasi Cr pada lokasi 1, 2 dan 3 di waduk Gajah Mungkur. Gambar 6 menunjukkan distribusi konsentrasi unsur logam $\mathrm{Cr}$ total terhadap total keseluruhan unsur logam $\mathrm{Cr}$ di dalam waduk Gajah Mungkur 


\section{Jurnal Forum Nuklir, tahun, Volume (Nomor)}

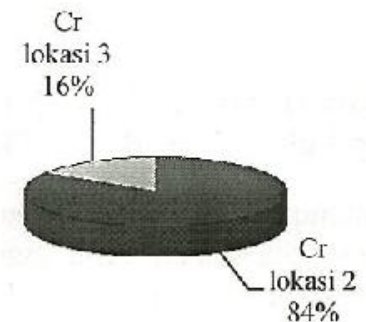

Gambar 6. Distribusi Konsentrasi Unsur Logam Cr 'Total Terhadap Total Keseluruhan Unsur Logam Cr di Dalam Waduk Gajah Mungkur

Untuk lokasi 1 pada Gambar 6 kandungan unsur logam $\mathrm{Cr}$ total tidak terdeteksi. Perbedaan distribusi konsentrasi pada lokasi-lokasi tersebut tergantung pada waktu tinggal unsur logam $\mathrm{Cr}$ total pada sedimen maupun keadan struktur sedimen waduk Gajah Mungkur. Lokasi 2 , berupa pasir dan debu serta lokasi 3 , berupa liat. Adapun konsentrasi $\mathrm{Cr}$ total pada lokasi 2 dan 3 sebesar 16,0 dan 3,0 ppm, atau perbandingan distribusi konsentrasi unsur logam tersebut di dalam sedimen terhadap total keseluruhan unsur logam $\mathrm{Cr}$ yang ada di dalam waduk adalah $84 \%$ pada lokasi 2 dan $16 \%$ pada lokasi 3.

\section{KESIMPULAN}

Berdasarkan penelitian yang telah dilakukan dapat ditarik beberapa kesimpulan yaitu:

1. Unsur Fe di waduk Gajah Mungkur terdeteksi pada lokasi 1 (aliran air masuk waduk), 2 (dekat keramba ikan) dan 3 (aliran air ke luar), Al terdeteksi pada lokasi 2 dan 3, Si terdeteksi pada lokasi I, dan Cr terdeteksi pada lokasi 1 dan 2.

2. Akurasi untuk logam $\mathrm{Fe}, \mathrm{Al}, \mathrm{Si}$ dan $\mathrm{Cr}$ total mempunyai kisaran: 5,25 - 10,75\%; presisi: 10,99 $14,25 \%$ dan batas deteksi untuk $\mathrm{Al}=1 \%, \mathrm{Na}=$ $0,14 \%, \mathrm{Mg}=0,05 \%, \mathrm{Si}=2 \%, \mathrm{Fe}=1 \%$ dan $\mathrm{Cr}=$ $0,01 \mathrm{ppm}$.

3. Konsentrasi kandungan unsur logam berat yang tersebar didalam sedimen untuk Fe berkisar 7,4 - $32 \%$ (berat); Al: 12 - $16 \%$ (berat); $\quad \mathrm{Si}: 40 \%$ (berat) dan Cr total: $3-16$ ppm.

\section{UCAPAN TERIMA KASIH}

Ucapan terima kasih kami sampaikan kepada Ibu Ellin Nuraini dan sdr. Sunardi, serta semua pihak atas semua bantuannya.

\section{DAFTAR PUSTAKA}

1. WEBSITE,http://id.wikipedia.org/wiki/Waduk_Gaja h Mungkur

2. $\mathrm{SD} \Lambda \mathrm{K}, \mathrm{CHAY}$., Hidrologi dan Pengelolaan Dacrah Aliran Sungai. Yogyakarta: Gadjah Mada University Press (2004)

3. WARDHANA, W, A, Dampak Pencemaran Lingkungan. Yogyakarta: Andi Offset (2004).
4. WISNU SUSETYO, Instrumentasi Kimia II, Pusdiklat Badan Tenaga Atom Nasional (1984).

5. HIROSHI KAMIOKI, Joint Training Course on Application of Nuclcar Technique in Indusry and Environment Available for the Safety of Nuclear Facility, Pusdiklat Batan, Jakarta, March, 1-12 (2004) 